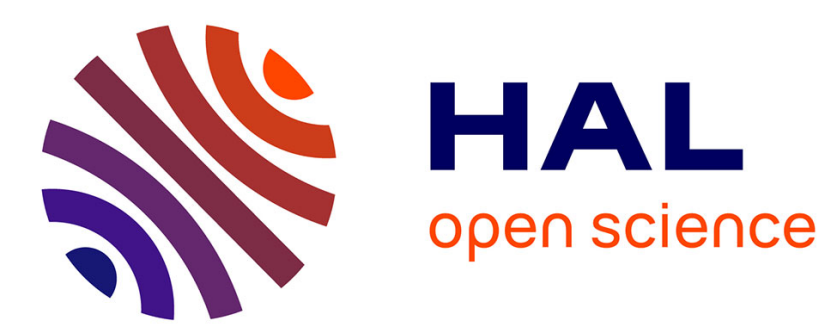

\title{
Higher and lower status individuals' performance goals: The role of hierarchy stability
}

Mickaël Jury, Alain Quiamzade, Céline Darnon, Gabriel Mugny

\section{To cite this version:}

Mickaël Jury, Alain Quiamzade, Céline Darnon, Gabriel Mugny. Higher and lower status individuals' performance goals: The role of hierarchy stability. Motivation Science, 2019, 5 (1), pp.52-65. $10.1037 / \operatorname{mot} 0000105$. hal-01859626

\section{HAL Id: hal-01859626 https://hal.science/hal-01859626}

Submitted on 5 Oct 2021

HAL is a multi-disciplinary open access archive for the deposit and dissemination of scientific research documents, whether they are published or not. The documents may come from teaching and research institutions in France or abroad, or from public or private research centers.
L'archive ouverte pluridisciplinaire HAL, est destinée au dépôt et à la diffusion de documents scientifiques de niveau recherche, publiés ou non, émanant des établissements d'enseignement et de recherche français ou étrangers, des laboratoires publics ou privés. 
Higher and Lower Status Individuals' Performance Goals:

The Role of Hierarchy Stability

\author{
Mickaël Jury ${ }^{1,2 *}$, Alain Quiamzade ${ }^{1,4,}$ Céline Darnon ${ }^{3,}$ Gabriel Mugny ${ }^{1}$ \\ 1 University of Geneva \\ ${ }^{2}$ ESPE Lille Nord de France, PSITEC, EA 4072 \\ ${ }^{3}$ Université Clermont Auvergne \\ ${ }^{4}$ Distance Learning University, Sierre, Switzerland
}

This paper has been accepted for publication in Motivation Science in 2018. This version is a postprint.

"ESPE Lille Nord de France, 365 Bis Rue Jules Guesde, 59650 Villeneuve-d'Ascq, France. Phone number: +333 207986 00. Email: mickael.jury@espe-Inf.fr.

This research was realized in the scope of the project « The Struggle for Competence in Academic Selection: Social Psychological Influences on Competence Threat » supported by the Swiss National Science Foundation.

The authors declare that there are no potential conflicts of interest with respect to the research, authorship, and/or publication of this article. 


\begin{abstract}
Compared to lower status individuals, higher status individuals are particularly likely to endorse approach (vs. avoidance) forms of motivation-notably, performance-approach goals (e.g., seeking to demonstrate superior competence) rather than performance-avoidance goals (e.g., seeking not to demonstrate inferior competence). In the present paper, we argue that this effect is likely to occur when the hierarchy is stable (i.e., in contexts in which mobility is not expected). Conversely, in unstable systems, pursuing both performance-approach goals and performance-avoidance goals might become relevant strategies, regardless of status. In two studies, performance-approach and performance-avoidance goals were measured and status was manipulated. Perception of hierarchy stability was either measured (Study 1) or manipulated (Study 2). The results of both studies supported that the difference between higher and lower status individuals in terms of performancebased goal orientation only appeared in stable hierarchical systems, sustaining a view of performancebased goals as dynamic processes resulting from the position one occupies in a hierarchical system.
\end{abstract}

Keywords: Status, hierarchy stability, achievement motivation, performance goals 


\section{Higher and Lower Status Individuals' Performance Goals: \\ The Role of Hierarchy Stability}

Status has been defined as the amount of prestige, respect, and esteem that an individual has in the eyes of others due to personal qualities or group belonging (Berger, Cohen, \& Zelditch, 1972; Blader \& Chen, 2014; Fiske, 2010). Status impacts cognitions, emotions and behaviors (for a review, see Cheng \& Tracy, 2014; Goudeau, Autin, \& Croizet, 2017) and is associated with numerous positive life outcomes (for examples, see Demakakos, Nazroo, Breeze, \& Marmot, 2008; Kraus, Piff, \& Keltner, 2009; Ridgeway, 2014; Sampson \& Sharlkey, 2008). In the present paper, we argue that status also impacts achievement motivation (i.e., performance-based goal orientation), specifically in contexts that are likely to sustain existing hierarchies.

\section{Status and Performance-based Goals}

Maintaining or gaining status is a fundamental motivation (Anderson, Hildreth, \& Howland, 2015; Anderson \& Kilduf, 2009; Sapolsky, 2005). According to earlier psychologists, producing performance grounded on some internal competence is particularly relevant to reach status (Brown, 1965; Parsons, 1951). Accordingly, Anderson et al. (2015) argued that individuals who sought to achieve status "must seem to possess competencies that are central to their own primary tasks and challenge" (p. 575; see also Anderson \& Kilduff, 2009; Driskell \& Mullen, 1990). Therefore, if they want to keep or gain status, people should demonstrate competence within tasks that are relevant in the given context to define the hierarchy.

The goals of demonstrating competence have been defined as performance-based goals (Elliot, 2005; Senko, 2016). In the achievement goal framework, performance-based goals are conceived as being either directed to approaching success (i.e., performance-approach goals, such as demonstrating superior ability) or avoiding failure (i.e., performance-avoidance goals, such as not demonstrating inferior ability; see Korn \& Elliot, 2016). Most of existing research on the antecedents of performance-based goal endorsement has focused on how individual characteristics predict these goals (e.g., Dinger, Dickhäuser, Spinath, \& Steynmar, 2013; Elliot \& Thrash, 2010), neglecting the very role of positional variables in explaining why individuals endorse some goals or others and in particular, performance-approach or avoidance goals (Darnon, Dompnier, \& Poortlviet, 2012). Indeed, if some scarce results suggest that higher status individuals (e.g., men, upper-class students) endorse more performance-approach goals and less performance-avoidance goals compared to lower status individuals (Anderman \& Midgley, 1997; Berger \& Archer, 2016; Chouinard \& Roy, 2008; Jury, Bruno, \& Darnon, 2018; Jury, Smeding, Court, \& Darnon, 2015; Senko \& Hulleman, 2013), it remains unknown how, and in which conditions, status can shape performance-based goal endorsement. In the present paper, we argue that more than individual dispositions, performance-based goals are dynamic processes (Gernigon, D’Arripe-Longueville, Delignières, \& Ninot, 2004) endorsed as a result of the position one occupies and plans to occupy in a hierarchical system.

Individuals at the top of the social heap live in reward-rich environments and have more success opportunities than those at the bottom (Fiske, 2010; Keltner, Gruenfeld, \& Aronson, 2003). To reach these opportunities, dominant individuals are more oriented toward approach strategies than 
dominated individuals (e.g., optimism, confidence, self-esteem; see Anderson \& Berdahl, 2002; Derks, Van Laar, \& Ellemers, 2006; Fast, Gruenfeld, Sivanathan, \& Galinsky, 2009; Guinote, 2017; Morrison, See, \& Pan, 2015; Smith \& Bargh, 2008; Wojciszke \& Struzynska-Kujalowicz, 2007). In addition, lower status individuals usually face (and perceive) more self-concept threats than higher status individuals (Kraus, Horberg, Goetz, \& Keltner, 2011; Kraus \& Park, 2014; Varnum \& Kitayama, 2017). For example, because of their supposed (Brambilla, Sacchi, Castellini, \& Riva, 2010; Fiske, Cuddy, Glick, $\& X u, 2002$ ) or actual (for an example on school performances, see Sirin, 2005) inferior level of competence, lower status individuals are likely to develop negative self-perceptions (Ivcevic \& Kaufman, 2013; Kraus \& Park, 2014; Rose \& Vogel, 2017). In addition, because of the weak social value associated with their group (Berger et al., 1972), lower status individuals are also likely to experience social identity threat (Bettencourt, Dorr, Charlton, \& Hume, 2001; Knight \& Metha, 2017; Pillaud, Rigaud, \& Clémence, 2015). To cope with these threatening states, lower status individuals are particularly likely to endorse avoidance strategies (e.g., performance-avoidance goals, Brodish \& Devine, 2009; Chalabaev, Sarrazin, Stone, \& Curry, 2008; Derks et al., 2006; Ryan \& Ryan, 2005).

To summarize, higher status individuals are more focused on attaining positive opportunities and less inclined to feel threatened than lower status individuals. Consequently, higher status individuals are oriented toward approach forms of motivation (including performance-approach goals) and less toward avoidance motivation (including performance-avoidance goals) than lower status individuals. However, most research that has examined the status differences presented thus far was conducted in stable contexts-namely, contexts in which social positions are not subject to change (Knight \& Metha, 2017). In the present paper, we argue that, as changes in hierarchies impact lower and higher status individuals' psychological functioning (Fiske, Dupree, Nicolas, \& Swencionis, 2016; Knight \& Metha, 2017), and as goals can be conceived as dynamic processes that depend on the place one occupies in a hierarchy, the stability of the system should also moderate the effect of status on performance-approach and performance-avoidance goal orientation.

\section{The Hierarchy Stability}

When hierarchies are stable over time, individuals in higher status positions and those in lower status positions respectively keep their privileged or unprivileged position (Sidanius \& Pratto, 1999; see also Blanden, Gregg, \& Machin, 2005). In these contexts, the status quo is secured. Higher status individuals' current position is not challenged, and lower status individuals have no real possibility of accessing more privileged positions (Scheepers, Röell, \& Ellemers, 2015). In such contexts, lower status individuals may permanently face the self-concept threat mentioned above and are then particularly likely to score high on performance-avoidance (rather than -approach) goals while higher status individuals should score higher on performance-approach (rather than -avoidance) goals (Chalabaev et al., 2008; for examples involving stress-based measures, see Feenstra, Jordan, Walter, Yan, \& Stoker, 2017; Jordan, Sivanathan, \& Galinsky, 2011).

In comparison, when the hierarchy is perceived as unstable, both high and low status individuals can face (downward or upward, respectively) mobility. Indeed, in such a context, lower status individuals can either escape their unprivileged position or fail to improve it. In a similar way, higher status individuals can either lose their privileged position-a situation that could become 
threatening—or keep their privileged position (see notably Knight \& Metha, 2017). In such circumstances, everyone may therefore be concerned about both maintaining or acquiring status (thereby endorsing performance-approach goals) and avoiding losing status (thereby endorsing performance-avoidance goals). In other words, in a system in which the hierarchy is unstable, pursuing performance-approach goals and performance-avoidance goals might both be relevant strategies to endorse regardless of actual status. Thus, the expected difference between higher and lower status individuals in terms of performance-approach and performance-avoidance goal orientations should no longer appear when the status quo is potentially challenged (unstable hierarchy; for a similar reasoning regarding inter-group status differences, see Scheepers, 2009; Tajfel \& Turner, 1979).

Indirect evidence supports this hypothesis. First, Scheepers and colleagues (2015) demonstrated that dominant individuals were more oriented toward challenge than threat compared to dominated people when the hierarchy was stable, but not when the hierarchy was unstable. Second, dominated individuals are less oriented toward approach strategies (e.g., risk taking, competitive behaviors) compared to dominant individuals only when the hierarchy is not subject to change or legitimate (Hays \& Benderski, 2015; Lammers, Galinsky, Gordijn, \& Otten, 2008; see also Maner, Gailliot, Butz, \& Peruche, 2007). Finally, and more importantly, Knight and Metha (2017) recently demonstrated that higher status individuals felt more in control, performed better, and showed greater dominance and warmth in a job interview than lower status individuals only when the hierarchy was stable; no such difference appeared in an unstable hierarchical system.

\section{Overview of the Present Paper}

Based on the argumentation presented thus far, we contend that, when the hierarchy between individuals is perceived as stable, higher status individuals should be more oriented toward performance-approach goals and less toward performance-avoidance goals compared to lower status individuals. This pattern is no longer expected when the hierarchy is perceived as unstable. Two studies tested this interaction hypothesis by measuring performance-approach and performanceavoidance goals and manipulating the status. Perception of hierarchy stability was either measured (Study 1) or manipulated (Study 2$){ }^{1}$

\section{Study 1}

\section{Method}

Participants. A convenient sample of 102 undergraduates from a French-speaking university consented to participate in a computer-based study; one participant who did not understand the instructions was excluded. The final sample included 101 participants (17 males and 84 females, Mage $\left.=21.05, S D_{\text {age }}=5.17\right)^{2}$

\footnotetext{
${ }^{1}$ All material and data presented in this manuscript can be accessed at: https://osf.io/ea2xf ${ }^{2}$ In the two studies, the results did not change when deleted participants were included in the analyses.
} 
Procedure and materials. Participants came to the lab in groups (i.e., around 20 participants per session) and were seated individually in front of computers. At the very beginning of the study, participants read that the current research focused on individuals' "perception style." Specifically, participants learned that individuals could be divided into groups depending on their perception style: those with an "analytic" perception style and those with a "holistic" perception style. Participants were then invited to complete two bogus tasks allegedly assessing their perception style. The first task was an association task comprising 10 items. Participants were asked to identify a word or a picture that did not fit into a set of four items (for a similar task, see Scheepers \& Ellemers, 2005). To strengthen the cover story, the participants were asked to complete a second task in which they were shown six optical illusions that combined two pictures (e.g., a duck and a rabbit). They were asked to identify the picture they saw first. Half of the participants were then randomly told that they had a "holistic" perception style while the other half were told that they had an "analytic" perception style.

To manipulate the status associated with their group, participants received bogus information about the social standing of each group on an intellectual dimension (i.e., abstract reasoning). The assignation to one of the two status conditions (lower vs. higher) was determined by the computer on a random basis. The participants in the lower status condition $(n=58)$ read that their group (analytic or holistic, depending on their random categorization) stood lower than the other group on abstract reasoning. The participants in the higher status condition $(n=43)$ read the opposite. ${ }^{3}$ Participants then received instructions about a new task presented as an efficient way to measure abstract reasoning. They subsequently completed the achievement goal questionnaire, the task and the manipulation check questions, as well as the measure of perceived hierarchy stability. They were then fully debriefed.

Performance goals. In the present studies, participants completed a performance-based achievement goals questionnaire (Korn \& Elliot, 2016) comprising 6 items ( 3 for each goal) measuring their endorsement of performance-approach (e.g., "My goal is to demonstrate ability") and performance-avoidance (e.g., "My aim is to avoid showing incompetence") goals for the following task. The participants indicated their degree of agreement with each item on a 7-point scale ranging from 1 "totally disagree" to 7 "totally agree." The average of each scale and the relative performance-based goals score between the endorsement of performance-approach goals and the endorsement of performance-avoidance goals were computed (see Chalabaev et al., 2008; Stoeber \& Crombie, 2010; Stoeber, Uphill, \& Hotham, 2009). Higher scores indicate that participants were more oriented toward performance-approach goals than performance-avoidance goals.

Hierarchy stability perception. Participants' perception of hierarchy stability was measured with items assessing the extent to which they believed that the dimension-sustaining status within this study (i.e., intellectual abilities in abstract reasoning) was stable. Indeed, we reasoned that the participants who thought that this dimension was stable would believe that the hierarchy between the two groups would also be stable. As a result, the participants completed three items measuring the extent to which they thought that such capacities are stable over time (e.g., "It is hard to change your level of intelligence"; see Da Fonseca, Cury, Bailly, \& Rufo, 2004). All items were reverse coded.

\footnotetext{
${ }^{3}$ The discrepancy in the number of participants is due to a randomization bias.
} 
Higher scores indicate that participants perceived the hierarchy as more unstable. Intercorrelations among variables, means, and reliabilities are presented in Table 1.

Table 1

Descriptive statistics and zero-order correlations (Study 1).

\begin{tabular}{lcccccc}
\hline \multicolumn{1}{c}{ Variables } & $M$ & $S D$ & $\alpha$ & 1 & 2 & 3 \\
\hline 1. Performance-approach goals & 4.00 & 1.36 & .70 & - & & \\
2. Performance-avoidance goals & 3.44 & 1.63 & .85 & .60 & - & \\
3. Perception of hierarchy stability & 4.53 & 1.18 & .67 & .02 & -.11 & - \\
4. Status & - & - & - & -.03 & -.07 & .04 \\
\hline
\end{tabular}

Note. Status was scored -0.5 for lower status and +0.5 for higher status.

${ }^{* *} p<.01$.

Manipulation checks. Participants answered two items measuring their group affiliation (e.g., "According to the test results, what group do you belong to?"; "According to you, what is your perception style?", $r=.66, p<.001, M=4.11, S D=1.67$ ) and two items measuring their group status based on alleged performance (e.g., "According to previous studies, which group has the best performances on abstract reasoning?"; "According to you, which group has the higher level of performance?", $r=.34, p<.001, M=4.10, S D=1.23$ ) on a 7-point scale ranging from 1 "the holistic group" to 7 "the analytic group."

\section{Results}

Manipulation checks. Regression analyses, including participants' status (coded -0.5 for lower status, +0.5 for higher status), participants' group (coded -0.5 for "holistic" and +0.5 for "analytic"), and the interaction between these two variables, were conducted on group affiliation and group status. A significant main effect of participants' group was observed on group affiliation, $B=$ 2.53, $S E=0.23, t(97)=11.14, p<.001, \eta_{p}^{2}=.56,95 \%$ Cls [2.07, 2.97], confirming that holistic group members $(M=2.88, S E=.16)$ and analytic group members $(M=5.41, S E=.16)$ properly reported their group affiliation. As far as group status is concerned, the interaction effect between participants' status and group was significant, $B=3.21, S E=0.38, t(97)=8.53, p<.001, \eta_{p}^{2}=.42,95 \%$ Cls $[2.46$, 3.95]. Among holistic group members, those with higher status $(M=3.38, S E=0.22)$ were more likely to choose the holistic group as the best group than lower status participants $(M=4.83, S E=0.15)$. Conversely, among analytic group members, higher status participants $(M=4.65, S E=0.18)$ were less likely to choose the holistic group as the best one than lower status participants ( $M=2.89, S E=0.19$ ). No other effects reached significance.

Main analysis. The regression model integrated three predictors: participants' status, participants' perception of hierarchy stability (mean-centered), and the interaction between these two 
variables. Preliminary analyses also included participants' group (i.e., holistic vs. analytic). As this variable had no effect on the results, it was removed from the analysis.

No main effect of participants' status, $t(97)<1$, or participants' perception of stability, $t(97)<1$, appeared on the performance goal orientation score. However, the interaction between these two variables was significant, $B=-0.52, S E=0.24, t(97)=-2.14, p=.035, \eta p^{2}=.04,95 \%$ Cls $[-1.00$, 0.03 ]. The simple slope for lower status participants was significant, $B=0.33, S E=0.14, t(97)=2.42$, $p=.017, \eta_{\mathrm{p}}^{2}=.05,95 \% \mathrm{Cls}[0.06,0.60]$, indicating that the more they perceived boundaries as unstable, the more they were oriented to performance-approach goals (as opposed to performanceavoidance goals). For higher status participants, the simple effect slope was in the expected direction but did not reach significance, $B=-0.19, S E=0.20, t(97)=-0.95, p=.34, \eta_{p}^{2}=.00,95 \%$ Cls $[-0.59$, 0.20]. In addition, as shown in Figure 1, for those who perceived the hierarchy as relatively stable (i.e., one standard deviation below the mean), higher status participants tended to be more oriented toward performance-approach goals and less toward performance-avoidance goals than lower status participants, $B=0.75, S E=0.40, t(97)=1.89, p=.062, \eta_{p}^{2}=.03,95 \%$ Cls $[-0.03,1.54]$. This difference did not emerge for those who perceived the hierarchy as rather unstable (i.e., one standard deviation above the mean), $B=-0.48, S E=0.39, t(97)=-1.24, p=.22, \eta_{p}^{2}=.01,95 \%$ Cls $[-1.25$, $0.29] .^{4}$

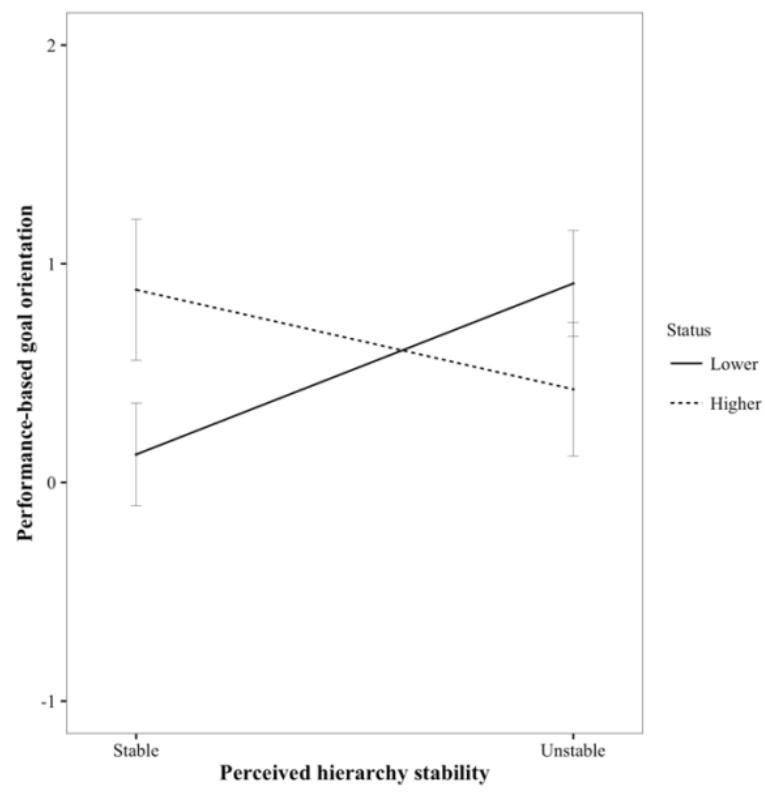

Figure 1. Performance-based goal orientation depending on status and perception of stability (Study 1). The higher the score, the higher the orientation toward performance-approach goals compared to performance-avoidance goals. Error bars represent standard error of the mean.

\footnotetext{
${ }^{4}$ As using difference scores is sometimes discussed in the literature (Cronbach \& Furby, 1970; Schoemann, Gallagher, \& Little, 2015), additional analyses were used to test our hypotheses on residual scores-namely, on the residual variance that remains when a performance goal (i.e., either approach or avoidance) is regressed on the other. These additional analyses showed that the interaction between status and participants' perception of hierarchy stability was significant for performance-approach goals $(p=.017)$ and marginally significant for performance-avoidance goals ( $p$ $=.091)$. No other effects reached significance (all $p s>.46$ ).
} 


\section{Discussion}

Study 1 tested whether status influenced performance-based goal orientation depending on hierarchy stability perception. When the hierarchy is stable, the status quo is secure: Higher status individuals' privileged position is not challenged, and lower status individuals are not able to increase their own position. Consequently, it was expected that-among those who perceive the hierarchy as stable-higher status individuals should be more oriented toward performance-approach goals and less toward performance-avoidance goals than lower status individuals, a pattern which was not expected for individuals who perceive the hierarchy as unstable (Knight \& Metha, 2017; Scheepers et al., 2015). The results supported the hypotheses. Indeed, higher status individuals who perceived the hierarchy as stable tended to endorse more performance-approach goals and less performanceavoidance goals compared to their lower status counterparts. This pattern did not emerge among participants who perceived the hierarchy as rather unstable, sustaining the view of goals as dynamic (and not stable) processes resulting from particular situational incentives (Gernigon et al., 2004).

Some limitations of this first study should be highlighted. First, it appeared that our status manipulation (see Scheepers \& Ellemers, 2005) was maybe not optimal as it also intrinsically manipulated the level of competence assigned to each group. Higher status participants read that they stood higher on the intellectual dimension; thus, they probably perceived themselves as having both a higher status and a higher level of competence than lower status participants. Such a situation makes it difficult to disentangle whether the effects obtained here reflected an effect of status or a mere effect of competence. Second, hierarchy stability was measured; thus, causal conclusion cannot be clearly established. Study 2 was thus designed to replicate these results while addressing these limitations.

\section{Study 2}

\section{Method}

Participants. A convenient sample of 146 undergraduates from a French-speaking university consented to participate in this study. Three participants were excluded from the final sample; two discovered the purpose of the study, and one did not understand the instructions. The final sample included 143 participants: 34 men and 107 women (2 missing values, $M$ age $=22.30, S D_{\text {age }}=7.18$ ).

Procedure and materials. Participants were initially informed that the study was split into two sessions and that the second one would allegedly take place one week later at the same place (see below for the rationale). At the beginning of the first session, each participant was randomly paired with another participant to form a dyad, with the condition that they should not know each other. Participants were randomly seated in front of two pre-installed notebooks, one for each, and were assigned to different social status positions. Then, they started working on a group decision-making task. After this collective task, participants were informed that they would do the same task but this time individually. At this point, hierarchy stability was manipulated and participants then had to complete the dependent measure assessing their performance-based goals within this individual task. Participants finally provided their own solution and ended the study by completing demographic information and receiving a full debriefing.

Task. In the notebook, participants read the instructions about a decision-making task (i.e., 
the moon survival task; Hall \& Watson, 1970). In this task, participants faced a crisis (i.e., a crash on the moon) and had to rank 15 items (e.g., oxygen, compass, rope, water) that could help them reach a safe spot (i.e., the mother ship) and finally survive. They had 10 minutes of discussion to propose the group's solution.

Status manipulation. The participants read within the task instructions that they had to roleplay either the pilot in charge of the mission (i.e., higher status, $n=71$ ) or the pilot's assistant (i.e., lower status, $n=72$ ) and that they would have to solve the task together. To strengthen the status manipulation, three elements were added to the procedure. First, participants read that the pilot would make the final group decision and could accept or reject the assistant's proposals without any justification. Second, participants were seated in different positions in an amphitheater; the notebooks for each pair were positioned in two seats behind each other so that the pilot was always seated above the assistant. During the group-decision task, lower status participants were asked to turn around in order to discuss with their higher status counterparts. Third, each dyad had only one pen with which to write down the group's decision. The assistant was informed that he/she had to wait until the pilot wrote the collective solution in his or her booklet before getting the pen and copying the same solution into his or her own notebook.

Hierarchy stability manipulation. After elaborating the group's decision, participants were informed that they would now have to provide an individual solution to the same task. They were told that their solution could be the same or different than the former group solution. However, before writing their own individual solution, participants read that they would have to participate to a similar task in an allegedly second session one week later. Participants in the unstable condition $(n=72)$ learned that the role they would play in this next session would depend on the quality of their individual answer to the task. More precisely, higher status participants were informed that they might keep their position or step back in the hierarchy (i.e., not be in charge). Conversely, lower status participants were informed that they might either keep their position or move forward in the hierarchy (i.e., be in charge of the decision). Participants in the stable condition $(n=71)$ learned that their role in the next session would be the same as the one they played in the first session.

Performance goal questionnaire. After receiving the instructions about the individual task, participants were asked to complete the performance-based goal questionnaire that included the same items as in Study 1. Participants had to report their goals within the individual decision task. The means, reliabilities, and correlations are presented in Table 2.

Manipulation checks. After the group task, participants completed two items on a 7-point scale to measure the perception of their own status in the dyad ("Within the group decision task, my status was [from 1, low to 7, high]"; "Please indicate to what extent you have status within the group decision task" [from 1, few to 7 , a lot]; $r=.72, p<.001, M=4.80, S D=1.19$ ). Then, after the individual task, participants completed two items assessing their perception of mobility possibilities ("My role in the second session (next week) will necessarily be identical to the one in this first session (today)" and "My role in the second session will be different to the one in this first session"-reverse-coded: $r=.55$, $p<.001, M=3.37, S D=1.46$ ) and two items assessing the role of the individual performance within mobility possibilities ("Roles in the second session will depend on participants' individual 
performances" and "Roles in the second session will be independent from participants' individual performances"-reverse-coded: $r=.66, p<.001, M=3.78, S D=1.80$ ).

Table 2

Descriptive statistics and zero-order correlations (Study 2).

\begin{tabular}{lccccc}
\hline \multicolumn{1}{c}{ Variables } & $M$ & $S D$ & $\alpha$ & 1 & 2 \\
\hline 1. Performance-approach goals & 4.01 & 1.29 & .85 & - & \\
2. Performance-avoidance goals & 4.01 & 1.45 & .88 & $.50^{* *}$ & - \\
3. Status & - & - & - & .07 & -.03 \\
4. Hierarchy stability & - & - & - & -.03 & -.03 \\
\hline
\end{tabular}

Note. Status was scored -0.5 for lower status and +0.5 for higher status; Hierarchy stability was scored -0.5 for "stable" and +0.5 for "unstable".

${ }^{* *} p<.01$.

\section{Results}

Manipulation checks. Regression analyses included participants' status (coded -0.5 for lower status, +0.5 for higher status), hierarchy stability (coded -0.5 for "stable" and +0.5 for "unstable"), and the interaction between these two variables. Participants in the higher status condition $(M=5.39, S E=$ $0.12)$ perceived their status as higher than participants in the lower status condition $(M=4.22, S E=$ $0.12), B=1.17, S E=0.17, t(139)=6.77, p<.001, \eta_{p}^{2}=.24,95 \% \mathrm{Cls}[0.82,1.51]$. No other effects reached significance. As far as hierarchy stability is concerned, compared to those in the stable condition $(M=2.56, S E=0.15)$, participants in the unstable condition $(M=4.15, S E=0.15)$ were more likely to believe that their position could change, $B=1.59, S E=0.21, t(137)=7.67, p<.001, \eta_{\mathrm{p}}^{2}$ $=.30,95 \%$ Cls $[1.18,2.00]$. Furthermore, participants in the unstable condition were more likely to believe that their performance in the individual task $(M=4.18, S E=0.21)$ would influence this mobility than those in the stable condition $(M=3.37, S E=0.21), B=0.81, S E=0.30, t(137)=2.72, p=.007$, $\eta_{p}{ }^{2}=.05,95 \% \mathrm{Cls}^{5}[0.22,1.39]$. No other effects reached significance.

Main analysis. Regressing performance-based goals on the same model indicated no main effect of participants' status, $t(139)=1.25$, $n s$, or of hierarchy stability, $t(139)<1$. However, the interaction between these two variables was significant, $B=-0.99, S E=0.45, t(139)=-2.19, p=.030$, $\eta_{p}^{2}=.03,95 \%$ Cls $[-1.88,-0.09]$. Although in the expected direction, the simple effect of hierarchy stability neither reached significance for lower status participants, $B=0.48, S E=0.32, t(139)=1.51, p$ $=.13,95 \% \mathrm{Cls}[-0.15,1.11]$, nor higher status participants, $B=-0.51, S E=0.32, t(139)=-1.59, p=$ $.11,95 \%$ Cls $[-1.14,0.12]$. However, as can be seen in Figure 2 , in the stable condition, higher status individuals ( $M=0.40, S E=0.21$ ) were more oriented toward performance-approach goals and less toward performance-avoidance goals than lower status participants $(M=-0.38, S E=0.23), B=0.78$,

\footnotetext{
${ }^{5}$ Variation in the degrees of freedom is due to missing data on some manipulation check items.
} 
$S E=0.32, t(139)=2.42, p=.017, \eta_{p}^{2}=.03,95 \%$ Cls $[0.14,1.41]$-a difference that did not appear in the unstable condition, $t(139)<1 .{ }^{6}$

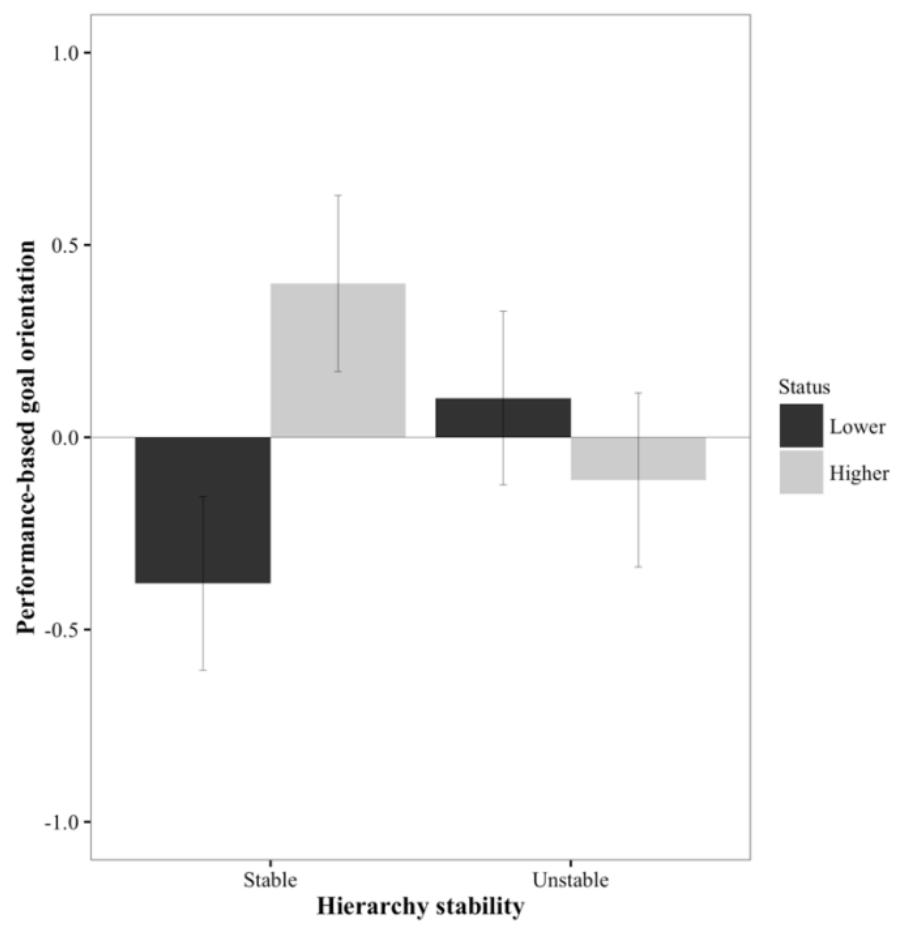

Figure 2. Performance-based goal orientation depending on status and stability (Study 2). The higher the score, the higher the orientation toward performance-approach goals compared to performanceavoidance goals. Error bars represent standard error of the mean.

\section{Discussion}

The significant interaction effect indicated that, when the hierarchy stability between groups was secured, higher status individuals were more oriented toward performance-approach goals and less toward performance-avoidance goals than lower status individuals. This pattern no longer appeared when the hierarchy between groups was unstable. These results replicated those of Study 1 while experimentally manipulating both participants' status and hierarchy stability. Moreover, the fact that Study 2 replicated Study 1's results with a manipulation of status that did not refer to competence supports our interpretation in terms of status per se rather than in terms of competence.

\section{General Discussion}

In the present paper, we argued that, when the status quo is secured, individuals' status should predict performance-based goal orientation. Indeed, in such a situation, higher status individuals are not afraid to lose their position and should therefore be more oriented toward performance-approach goals and less toward performance-avoidance goals in order to maintain their status. Conversely, lower status individuals have few hopes for improving-a context that is

\footnotetext{
${ }^{6}$ As in Study 1, analyses were also run on residual scores. The results for performance-approach goals indicated a marginal interaction between participants' status and hierarchy stability $(p=.075)$ and a significant interaction for performance-avoidance goals $(p=.050)$. No other effects reached significance (all $p s>.21$ ).
} 
susceptible to threaten their self-concept and orient them toward performance-avoidance goals (Brodish \& Devine, 2009; Chalabaev et al., 2008; Scheepers, 2013). In contrast, when the hierarchy is unstable, both upward and downward mobility are possible - that is, the position of lower and higher status individuals can change (Knight \& Metha, 2017; Scheepers et al., 2015) and endorsing performance-approach and performance-avoidance goals could become an appropriate strategy to follow for both lower and higher status individuals. As a result, we hypothesized that, when the hierarchy between the groups is stable, higher status individuals would be more oriented toward performance-approach goals and less toward performance-avoidance goals than lower status participants, and that this pattern would disappear when the hierarchy between groups is unstable (Knight \& Metha, 2017; Scheepers et al., 2015; see also, Scheepers, 2009; Scheepers, Ellemers, \& Sintemaartensdijk, 2009;). The two studies presented herein supported this reasoning as the performance-based goal orientation of higher and lower status individuals differed in the predicted direction but only when the hierarchy was stable. No such effect of status appeared in unstable hierarchical systems.

In line with recent conceptualizations in the achievement goal literature (Butler, 2006; Dompnier, Darnon, \& Butera, 2009, 2013; Dompnier, Darnon, Delmas, \& Butera, 2008; Jury, Smeding, \& Darnon, 2015; Pekrun, Cusack, Murayama, Elliot, \& Thomas, 2014), the present results sustain that achievement goals are not stable constructs, but rather dynamic cognitive representations that individuals can adjust depending on the demand of the context (i.e., individuals can modify their achievement of goal endorsement according to the system properties). In addition, by providing empirical evidence supporting a causal relationship between status and performance-based goal orientation -when the status quo is secured - this research strengthens former hypotheses (Elliot, 1999; see also Berger \& Archer, 2015; Darnon et al., 2012) as well as previous correlational results (Berger \& Archer, 2016; Dekker et al., 2013; Jury et al., 2018; Jury, Smeding, Court et al., 2015) according to which status should be considered as a key determinant of achievement goal endorsement. Finally, the moderating effect of the context (i.e., hierarchy stability) suggests that status may actually interact with social mobility opportunities for determining which goals individuals are likely to endorse.

Notwithstanding these conclusions, it should be noted that this work is limited due to the only use of self-report measures to investigate our hypotheses. First, self-report measures may be potentially biased by participants' willingness to present themselves in a positive way (Dompnier et al., 2013; Paulhus \& Vazire, 2005). Therefore, replicating the present results using a subtler measure of achievement goal orientation would certainly represent an added value (for a discussion on this point, see Da Costa \& Remedios, 2014; for an example, see Zhou \& Winne, 2012). Second, future research could also include behavioral measures of performance-based goal orientation, by replicating, for example, the present results with a behavioral measure of work investment inspired from Derks et al. (2006, see Study 2). In such a study, it would be reasonable to predict that when the hierarchy is stable, higher status participants should invest more in tasks allowing them to demonstrate their competences while lower status individuals should invest more in tasks allowing them no to 
demonstrate poor competences. Such differences would not be expected when the hierarchy is unstable.

As mentioned in the introduction, individuals strive to demonstrate competence precisely because showing competence can be conceived as a relevant and adaptive strategy to reach or to avoid losing high status (Anderson et al., 2015; Parsons, 1951). As such, the present research calls for more research that would consider the social position individuals occupy in a hierarchical system to understand the goals they pursue (Berger \& Archer, 2015; Darnon et al., 2012). In particular, the present findings underscore the vicious circle that lower status individuals may face in societies in which hierarchies are stable. In fact, performance-approach and performance-avoidance goals are forms of motivations that can contribute to reproducing the status quo. Indeed, research has largely supported that approach-oriented strategies are positively associated with positive outcomes (including performance) whereas avoidance-oriented strategies are consistently related to negative outcomes (Gorman et al., 2012; Harackiewicz, Barron, Pintrich, Elliot, \& Thrash, 2002; Van Yperen, Blaga, \& Postmes, 2014). Thus, when the status quo is secured, individuals may be pushed to endorse adaptive (for higher status) or maladaptive (for lower status) forms of motivations. In fine, this may contribute to the reproduction of the social order by putting lower status individuals in poorer conditions to reach success and status and, thus, achieve upward mobility. In other words, the present paper shows how motivational orientation (i.e., goals) of low status individuals can be one of the factors contributing to reducing their opportunity for upward mobility, as it may prove particularly efficient for maintaining the status quo (Sidanius \& Pratto, 1999). 


\section{References}

Anderman, E. M., \& Midgley, C. (1997). Changes in achievement goal orientations, perceived academic competence, and grades across the transition to middle-level schools. Contemporary Educational Psychology, 22, 269-298. doi: 10.1006/ceps.1996.0926

Anderson, C., \& Berdahl, J. L. (2002). The experience of power: Examining the effects of power on approach and inhibition tendencies. Journal of Personality and Social Psychology, 83(6), 1362-1377. doi: 10.1037//0022-3514.83.6.1362

Anderson, C., Hildreth, J. A. D., Howland, L. (2015). Is the desire for status a fundamental human motive? A review of the empirical literature. Psychological Bulletin, 141(3), 574-601. doi: 10.1037/a0038781

Anderson, C., \& Kilduff, G. J. (2009). The pursuit of status in social groups. Current Directions in Psychological Science, 18(5), 295-298. doi: 10.1111/j.1467-8721.2009.01655.x

Berger, J., Cohen, B. P., \& Zelditch, M. (1972). Status characteristics and social interaction. American Sociological Review, 37(3), 241-255.

Berger, N., \& Archer, J. (2015). The relationship between social class and students' academic achievement goals. The Routledge International Handbook Of Social Psychology Of the Classroom, (pp. 31-41). Abingdon: Routledge. doi: 10.4324/9781315716923.ch3

Berger, N., \& Archer, J. (2016). School socio-economic status and student socio-academic achievement goals in upper secondary contexts. Social Psychology of Education, 19(1), 175194. doi: $10.1007 / \mathrm{s} 11218-015-9324-8$

Bettencourt, B. A., Charlton, K., Dorr, N., \& Hume, D. L. (2001). Status differences and in-group bias: A meta-analytic examination of the effects of status stability, status legitimacy, and group permeability. Psychological Bulletin, 127(4), 520-542. doi: 10.1037//0033-2909.127.4.520

Blader, S. L., \& Chen, Y. (2014). What's in a name? Status, power, and other forms of social hierarchy. In J. T. Cheng, J. L. Tracy, \& C. Anderson (Eds.), The Psychology of Social Status (pp. 71-95). New York, NY US: Springer-Verlag. doi: 10.1007/978-1-4939-0867-7

Blanden, J., Gregg, P., \& Machin, S. (2005). Intergenerational Mobility in Europe and North America. Retrieved from http://citeseerx.ist.psu.edu/viewdoc/download?doi=10.1.1.84.5218\&amp;rep=rep1\&amp;type= pdf

Brambilla, M., Sacchi, S., Castellini, F., \& Riva, P. (2010). The effects of status on perceived warmth and competence: Malleability of the relationship between status and stereotype content. Social Psychology, 41(2), 82-87. doi: 10.1027/1864-9335/a000012

Brodish, A. B., \& Devine, P. G. (2009). The role of performance-avoidance goals and worry in mediating the relationship between stereotype threat and performance. Journal of Experimental Social Psychology, 45(1), 180-185. doi: 10.1016/j.jesp.2008.08.005

Brown, R. (1965). Social Psychology. New York: Free Press.

Butler, R. (2006). Are mastery and ability goals both adaptive? Evaluation, initial goal construction and the quality of task engagement. British Journal of Educational Psychology, 76(3), 595-611. doi: 10.1348/000709905X52319 
Chalabaev, A., Sarrazin, P., Stone, J., \& Cury, F. (2008). Do achievement goals mediate stereotype threat? An investigation on females' soccer performance. Journal of Sport and Exercise Psychology, 30(2), 143-158. Retrieved from https://www.ncbi.nlm.nih.gov/pubmed/18490787

Cheng, J. T., Tracy, J. L., \& Anderson, C. (2014). The Psychology of Social Status. New York, NY US: Springer-Verlag. doi: 10.1007/978-1-4939-0867-7

Chouinard, R., \& Roy, N. (2008). Changes in high-school students' competence beliefs, utility value and achievement goals in mathematics. British Journal of Educational Psychology, 78(1), 3150. doi: 10.1348/000709907X197993

Cronbach, L. J., \& Furby, L. (1970). How we should measure "change" - or should we? Psychological Bulletin, 74(1), 68-80. doi: 10.1037/h0029382

Da Costa, L., \& Remedios, R. (2014). Different methods, different results: Examining the implications of methodological divergence and implicit processes for achievement goal research. Journal of Mixed Methods Research, 8(2), 162-179. doi: 10.1177/1558689813495977

Da Fonseca, D., Cury, F., Bailly, D., \& Rufo, M. (2004). Théories implicites de l'intelligence et buts d'accomplissement scolaire [Implicit theories of intelligence and school achievement goal]. Annales Médico-Psychologiques, 162(9), 703-710. doi: 10.1016/j.amp.2004.04.019

Darnon, C., Dompnier, B., \& Poortvliet, M. (2012). Achievement goals in educational contexts: A social psychology perspective. Social and Personality Psychology Compass, 6(10), 760-771. doi: 10.1111/j.1751-9004.2012.00457.x

Dekker, S., Krabbendam, L., Lee, N. C., Boschloo, A., de Groot, R., \& Jolles, J. (2013). Sex differences in goal orientation in adolescents aged 10-19: The older boys adopt work-avoidant goals twice as often as girls. Learning and Individual Differences, 26, 196-200. doi: 10.1016/j.lindif.2012.07.011

Demakakos, P., Nazroo, J., Breeze, E., \& Marmot, M. (2008). Socioeconomic status and health: The role of subjective social status. Social Science and Medicine, 67(2), 330-340. doi: 10.1016/j.socscimed.2008.03.038

Derks, B., van Laar, C., \& Ellemers, N. (2006). Striving for success in outgroup settings: Effects of contextually emphasizing ingroup dimensions on stigmatized group members' social identity and performance styles. Personality and Social Psychology Bulletin, 32(5), 576-88. doi: $10.1177 / 0146167205283336$

Dinger, F. C., Dickhäuser, O., Spinath, B., \& Steinmayr, R. (2013). Antecedents and consequences of students' achievement goals: A mediation analysis. Learning and Individual Differences, 28, 90-101. doi: 10.1016/j.lindif.2013.09.005

Dompnier, B., Darnon, C., \& Butera, F. (2009). Faking the desire to learn. Psychological Science, 20(8), 939-943. doi : 10.1111/j.1467-9280.2009.02384.x

Dompnier, B., Darnon, C., \& Butera, F. (2013). When performance-approach goals predict academic achievement and when they do not: A social value approach. British Journal of Social Psychology, 52(3), 587-596. doi: 10.1111/bjso.12025 
Dompnier, B., Darnon, C., Delmas, F., \& Butera, F. (2008). Achievement goals and social judgment: The performance-approach goals paradox. International Review of Social Psychology, 21(1), 247-271. Retrieved from http://www.cairn.info/resume.php?ID_ARTICLE=RIPSO_211_0247

Driskell, J. E., \& Mullen, B. (1990). Status, expectations, and behavior: A meta-analytic review and test of the theory. Personality and Social Psychology Bulletin, 16(3), 541-553. doi: 10.1177/0146167290163012

Elliot, A. J. (1999). Approach and avoidance motivation and achievement goals. Educational Psychologist, 34(3), 169-189. doi:10.1207/s15326985ep3403_3.

Elliot, A. J. (2005). A conceptual history of the achievement goal construct. In A. Elliot and C. Dweck (Eds.), Handbook of Competence and Motivation (pp. 52-72). New York, NY: Guilford Press.

Elliot, A. J., \& Thrash, T. M. (2010). Approach and avoidance temperament as basic dimensions of personality. Journal of Personality, 78(3), 865-906. doi: 10.1111.j.1 467-6494.2010.00636.x

Fast, N. J., Gruenfeld, D. H., Sivanathan, N., \& Galinsky, A. D. (2009). Illusory control: A generative force behind power's far-reaching effects. Psychological Science, 20(4), 502-508. doi: 10.1111/j.1467-9280.2009.02311.x

Feenstra, S., Jordan, J., Walter, F., Yan, J., \& Stoker, J. I. (2017). The hazard of teetering at the top and being tied to the bottom: The interactive relationship of power, stability, and social dominance orientation with work stress. Applied Psychology, 66(4), 653-673. doi: 10.1111/apps.12104

Fiske, S. T. (2010). Interpersonal stratification. Status, power, and subordination. In S. T. Fiske, D. T. Gilbert, \& G. Lindzey (Eds.), Handbook of Social Psychology (5th ed., pp. 941-982). Hoboken, NJ US: Wiley. doi: 10.1037/h0039639

Fiske, S. T., Cuddy, A. J. C., Glick, P., \& Xu, J. (2002). A model of (often mixed) stereotype content: Competence and warmth respectively follow from perceived status and competition. Journal of Personality and Social Psychology, 82(6), 878-902. doi: 10.1037/0022-3514.82.6.878

Fiske, S. T., Dupree, C. H., Nicolas, G., \& Swencionis, J. K. (2016). Status, power, and intergroup relations: the personal is the societal. Current Opinion in Psychology, 11, 44-48. doi: 10.1016/j.copsyc.2016.05.012

Gernigon, C., D’Arripe-Longueville, F., Delignières, D., \& Ninot, G. (2004). A dynamical systems perspective on goal involvement states in sport. Journal of Sport \& Exercise Psychology, 26, 572-596. http://journals.humankinetics.com/doi/abs/10.1123/jsep.26.4.572

Gorman, C. A., Meriac, J. P., Overstreet, B. L., Apodaca, S., McIntyre, A. L., Park, P., \& Godbey, J. N. (2012). A meta-analysis of the regulatory focus nomological network: Work-related antecedents and consequences. Journal of Vocational Behavior, 80, 160-172. doi: 10.1016/j.jvb.2011.07.005

Goudeau, S., Autin, F., \& Croizet, J.-C. (2017). Etudier, mesurer et manipuler la classe sociale en psychologie sociale: Approches économiques, symboliques et culturelles [Studying, measuring and manipulating social class in social psychology: Economic, symbolic and 
cultural approaches]. International Review of Social Psychology, 30(1), 1-19. doi: 10.5334/irsp.5

Guinote, A. (2017). How power affects people: Activating, wanting, and goal seeking. Annual Review of Psychology, 68, 353-381. doi: 10.1146/annurev-psych-010416-044153

Hall, J., \& Waston, W. H. (1970). The effects of a normative intervention on group decision-making performance. Human Relations, 23(4), 299-317. doi: 10.1177/001872677002300404

Harackiewicz, J. M., Barron, K. E., Pintrich, P. R., Elliot, A. J., \& Thrash, T. M. (2002). Revision of achievement goal theory: Necessary and illuminating. Journal of Educational Psychology, 94(3), 638-645. doi: 10.1037/0022-0663.94.3.638

Hays, N. A., \& Bendersky, C. (2015). Not all inequality is created equal: Effects of status versus power hierarchies on competition for upward mobility. Journal of Personality and Social Psychology, 108(6), 867-882. doi: 10.1037/pspi0000017

Ivcevic, Z., \& Kaufman, J. C. (2013). The can and cannot do attitude: How self-estimates of ability vary across ethnic and socioeconomic groups. Learning and Individual Differences, 27, 144-148. doi: 10.1016/j.lindif.2013.07.011

Jordan, J., Sivanathan, N., \& Galinsky, A. D. (2011). Something to lose and nothing to gain: The role of stress in the interactive effect of power and stability on risk taking. Administrative Science Quarterly, 56(4), 530-558. doi: 10.1177/0001839212441928

Jury, M., Bruno, A., \& Darnon, C. (2018). Doing better (or worse) than one's parents: Social status, mobility and performance-avoidance goals. Manuscript accepted for publication in the British Journal of Educational Psychology. doi: 10.1111/bjep.12210

Jury, M., Quiamzade, A., Darnon, C., \& Mugny, G. (2018). Status, Hierarchy, Performance goals. Retrieved from osf.io/ea2xf

Jury, M., Smeding, A., Court, M., \& Darnon, C. (2015). When first-generation students succeed at university: On the link between social class, academic performance, and performanceavoidance goals. Contemporary Educational Psychology, 41, 25-36. doi: 10.1016/j.cedpsych.2014.11.001

Jury, M., Smeding, A., \& Darnon, C. (2015). Competing with oneself or with others: Achievement goal endorsement in amateur golf competition. International Journal of Sport Psychology, 45(6), 559-580. doi: 10.7352/IJSP

Keltner, D., Gruenfeld, D. H., \& Cameron, A. (2003). Power, approach, and inhibition. Psychological Review, 110(2), 265-284. doi: 10.1037/0033-295X.110.2.265

Knight, E. L., \& Mehta, P. H. (2017). Hierarchy stability moderates the effect of status on stress and performance in humans. Proceedings of the National Academy of Sciences of the United States of America, 114(1), 78-83. doi: 10.1073/pnas.1609811114

Korn, R. M., \& Elliot, A. J. (2016). The $2 \times 2$ standpoints model of achievement goals. Frontiers in Psychology, 7. doi: 10.3389/fpsyg.2016.00742 
Kraus, M. W., Horberg, E. J., Goetz, J. L., \& Keltner, D. (2011). Social class rank, threat vigilance, and hostile reactivity. Personality and Social Psychology Bulletin, 37(10), 1376-1388. doi: 10.1177/0146167211410987

Kraus, M. W., \& Park, J. W. (2014). The undervalued self: Social class and self-evaluation. Frontiers in Psychology, 5, 1-9. doi: 10.3389/fpsyg.2014.01404

Kraus, M. W., Piff, P. K., \& Keltner, D. (2009). Social class, sense of control, and social explanation. Journal of Personality and Social Psychology, 97(6), 992-1004. doi: 10.1037/a0016357

Lammers, J., Galinsky, A. D., Gordijn, E. H., \& Otten, S. (2008). Illegitimacy moderates the effects of power on approach. Psychological Science, 19(6), 558-564. doi: 10.1111/j.14679280.2008.02123.x

Maner, J. K., Gailliot, M. T., Butz, D. A., \& Peruche, B. M. (2007). Power, risk, and the status quo: Does power promote riskier or more conservative decision making? Personality and Social Psychology Bulletin, 33(4), 451-462. doi: 10.1177/0146167206297405

Morrison, E. W., See, K. E., \& Pan, C. (2015). An approach-inhibition model of employee silence: The joint effects of personal sense of power and target openness. Personnel Psychology, 68, 547580. doi: $10.1111 /$ peps. 12087

Parsons, T. (1951). The social system. Glencoe: Free Press.

Paulhus, D.L., Vazire, S. (2005). The self-report method. In R. W. Robins, R. C. Fraley, \& R. F. Krueger (Eds.), Handbook of Research Methods in Personality Psychology, (pp. 224-239). New York: Guilford.

Pekrun, R., Cusack, A., Murayama, K., Elliot, A. J., \& Thomas, K. (2014). The power of anticipated feedback: Effects on students' achievement goals and achievement emotions. Learning and Instruction, 29, 115-124. doi: 10.1016/j.learninstruc.2013.09.002

Pillaud, V., Rigaud, D., \& Clémence, A. (2015). The influence of chronic and situational social status on stereotype susceptibility. Plos One, 10(12), e0144582. doi: 10.1371/journal.pone.0144582

Ridgeway, C. L. (2014). Why status matters for inequality. American Sociological Review, 79(1), 1-16. doi: $10.1177 / 0003122413515997$

Rose, J. P., \& Vogel, E. (2017). Self-esteem and social status. In V. Zeigler-Hill \& T. K. Shackelford (Eds.), Encyclopedia of Personality and Individual Differences (pp. 1-4). Cham: Springer International Publishing. doi: 10.1007/978-3-319-28099-8_1172-1

Ryan, K. E., \& Ryan, A. M. (2005). Psychological processes underlying stereotype threat and standardized math test performance. Educational Psychologist, 40(1), 53-63. doi: 10.1207/s15326985ep4001_4

Sampson, R. J., \& Sharkey, P. (2008). Neighborhood selection and the social inequality. Demography, 45(1), 1-29. doi: 10.1353/dem.2008.0012

Sapolsky, R. M. (2005). The influence of social hierarchy on primate health. Science, 308(5722), 648652. doi: $10.1126 /$ science. 1106477

Scheepers, D. (2009). Turning social identity threat into challenge: Status stability and cardiovascular reactivity during inter-group competition. Journal of Experimental Social Psychology, 45(1), 228-233. doi: 10.1016/j.jesp.2008.09.011 
Scheepers, D. (2013). Social identity-based threats and challenges. In B. Derks, D. Scheepers \& N. Ellemers (Eds.), Neuroscience of prejudice and inter-group relations (pp. 243-259). New York, NY: Psychology Press.

Scheepers, D., \& Ellemers, N. (2005). When the pressure is up: The assessment of social identity threat in low and high status groups. Journal of Experimental Social Psychology, 41(2), 192200. doi: 10.1016/j.jesp.2004.06.002

Scheepers, D., Ellemers, N., \& Sintemaartensdijk, N. (2009). Suffering from the possibility of status loss: Physiological responses to social identity threat in high status groups. European Journal of Social Psychology, 39, 1075-1092. doi: 10.1002/ejsp

Scheepers, D., Röell, C., \& Ellemers, N. (2015). Unstable power threatens the powerful and challenges the powerless: Evidence from cardiovascular markers of motivation. Frontiers in Psychology, 6, 1-11. doi: 10.3389/fpsyg.2015.00720

Schoeman, A. M., Gallagher, M. W., \& Little, T. D. (2015). Difference scores. In R. L. Cautin \& S. O. Lilienfeld (Eds.), The Encyclopedia of Clinical Psychology (pp. 884-890). Wiley. doi: 10.1002/9781118625392.wbecp463

Senko, C. (2016). Achievement goal theory: A story of early promises, eventual discords, and future possibilities. In K. Wentzel \& D. Miele (Eds), Handbook of Motivation at School, Vol. 2 (pp. 7595). New York, NY: Taylor \& Francis.

Senko, C., \& Hulleman, C. S. (2013). The role of goal attainment expectancies in achievement goal pursuit. Journal of Educational Psychology, 105(2), 504-521. doi: 10.1037/a0031136

Sidanius, J., \& Pratto, F. (1999). Social dominance: An intergroup theory of social hierarchy and oppression. New York: Cambridge University Press. doi: 10.1017/CBO9781139175043

Sirin, S. R. (2005). Socioeconomic status and academic achievement: A meta-analytic review of research. Review of Educational Research, 75(3), 417-453. doi: 10.3102/00346543075003417

Smith, P. K., \& Bargh, J. A. (2008). Nonconscious effects of power on basic approach and avoidance tendencies. Social Cognition, 26(1), 1-24. doi: 10.1521/soco.2008.26.1.1

Stoeber, J., \& Crombie, R. (2010). Achievement goals and championship performance: Predicting absolute performance and qualification success. Psychology of Sport and Exercise, 11(6), 513-521. doi: 10.1016/j.psychsport.2010.07.007

Stoeber, J., Uphill, M. A., \& Hotham, S. (2009). Predicting race performance in triathlon: The role of perfectionism, achievement goals, and personal goal setting. Journal of Sport \& Exercise Psychology, 31(2), 211-245. doi: 10.1123/jsep.31.2.211

Tajfel, H., \& Turner, J. (1979). An integrative theory of intergroup conflict. In W. G. Austin \& S. Worchel (Eds.), The Social Psychology of Intergroup Relations (pp. 33-47). Monterey, CA: Brooks/Cole. doi: 10.1016/S0065-2601(05)37005-5

Van Yperen, N. W., Blaga, M., \& Postmes, T. (2014). A meta-analysis of self-reported achievement goals and nonself-report performance across three achievement domains (work, sports, and education). PLoS ONE, 9(4), e93594. doi: 10.1371/journal.pone.0093594 
Varnum, M. E. W., \& Kitayama, S. (2017). The neuroscience of social class. Current Opinion in Psychology, 18, 147-151. doi: 10.1016/j.copsyc.2017.07.032.

Wojciszke, B., \& Struzynska-Kujalowicz, A. (2007). Power influences self-esteem. Social Cognition, 25(4), 472-494. doi: 10.1521/soco.2007.25.4.472

Zhou, M., \& Winne, P. H. (2012). Modeling academic achievement by self-reported versus traced goal orientation. Learning and Instruction, 22(6), 413-419. doi:10.1016/j.learninstruc.2012.03.004 